\title{
Thyroid Function in Obese Children and Adolescents and its Relationships with Metabolic Parameters
}

\author{
(D) Özlem Korkmaz
}

Başkent University Faculty of Medicine, Dr Turgut Noyan Training and Research Center, Department of Pediatric Endocrinology, Adana, Turkey

\begin{abstract}
Aim: The purpose of this study was to evaluate levels of free thyroxin (T4) and thyroid-stimulating hormone (TSH) in obese children and adolescents, and to identify potential correlations between glucose and lipid metabolism parameters.

Materials and Methods: One hundred obese patients aged 8-18 years were retrospectively evaluated in the pediatric endocrinology outpatient clinic. All participants' anthropometric measurements, free T4 and TSH concentrations, glucose levels and lipid profiles were recorded.

Results: The mean age of the participants was $11.43 \pm 2.64$ years. TSH levels exhibited significant positive correlation with fasting blood glucose and cholesterol levels. Multiple regression analysis showed that a one-unit increase in blood glucose and cholesterol raised TSH levels by 0.047 units and 0.012 units, respectively.

Conclusion: The relationship between thyroid function and other metabolic risk factors in obese children is still unclear. Our findings are important in terms of showing that obesity may exert a central effect on thyroid function, before the emergence of any effects on insulin levels and anthropometric characteristics. A greater understanding of the association between thyroid function and obesity will be useful to the development of strategies aimed at preventing or treating childhood obesity.
\end{abstract}

Keywords: Childhood obesity, thyroid hormone, glucose levels, lipid profile

\section{Introduction}

Childhood obesity has become a major global health problem (1). As the prevalence of obesity increases, so does that of numerous comorbidities associated with obesity, including abnormalities in the endocrine, cardiovascular, gastrointestinal, pulmonary, orthopedic and neurologic systems, as well as important psychological and social problems. Some comorbidities, such as type 2 Diabetes Mellitus and steatohepatitis are extremely common in obese children, while thyroid dysfunctions are also frequently observed $(2,3)$. There has recently been increased interest in the association between thyroid dysfunction and obesity (4-6). The mechanisms underlying the thyroid hormone changes in obesity are unclear. However, several mechanisms have been proposed in the literature describing the different forms of thyroid dysfunction in obese individuals. These include subclinical hypothyroidism due to iodine deficiency, autoimmune thyroiditis and thyroid-stimulating hormone (TSH) receptor gene mutation, functional disorders in the hypothalamus-pituitary-thyroid axis, thyroid hormone resistance, mitochondrial dysfunction, and production

\section{Address for Correspondence}

Özlem Korkmaz MD, Başkent University Faculty of Medicine, Dr Turgut Noyan Training and Research Center, Department of Pediatric Endocrinology, Adana, Turkey Phone: +905054504915 E-mail: ozlem-korkmazz@hotmail.com ORCID: orcid.org/0000-0001-9093-6205

Received: 16.01.2019 Accepted: 09.02.2019

${ }^{\circ}$ Copyright 2020 by Ege University Faculty of Medicine, Department of Pediatrics and Ege Children's Foundation

The Journal of Pediatric Research, published by Galenos Publishing House. 
of Leptin-mediated pro-Thyrotropin-releasing hormone $(\mathrm{TRH})(7,8)$. Thyroid hormones are known to affect the regulation of energy homeostasis, fat oxidation, and lipid and carbohydrate metabolism. Increased TSH levels are therefore regarded as indicative of the changing energy balance in obesity $(9,10)$.

TSH level elevation has been associated with high triglyceride (TG), low-density lipoprotein cholesterol (LDLC), and total cholesterol (TC) levels, insulin resistance, and a risk of coronary disease in obese children $(11,12)$. However, it is unclear whether obesity and TSH levels have an 'adaptive association', whether the metabolic rate increases in order to reduce weight gain, whether an increase occurs in subclinical hypothyroidism or thyroid resistance, and therefore, whether obesity contributes to the dysfunctions in glucose and/or lipid metabolism, or is instead a by-product of increased weight.

Few studies to date have focused on the relationship between obesity and thyroid function in Turkish children and adolescents (13-16). Furthermore, the relationship between thyroid function and other metabolic risk factors in obese children is unclear. This research was intended to evaluate levels of free thyroxin (T4) and TSH in obese children and adolescents, and to identify potential correlations between glucose and lipid metabolism markers.

\section{Materials and Methods}

One hundred obese patients aged 8-18 years were retrospectively evaluated in the pediatric endocrinology outpatient clinic between 01 September, 2018, and 20 December, 2018.

Ethical approval was obtained from Başkent University Faculty of Medicine Ethical Committee (approval number: KA19/27). The current study was conducted according to the principles set out in the Helsinki Declaration and Good Clinical Practice guidelines. Informed consent was obtained.

Subjects with chronic medication requirements, who declined to take part, with underlying chronic disease, or diagnosed with syndromic obesity were excluded from the study.

Anthropometric data, including weight, weight Standard Deviation score (SDS), height, height SDS, Body Mass index (BMI) and BMI SDS, were recorded for all subjects. All anthropometric data were converted to SDSs using Turkish standard data (17). Subjects with BMI SDS $>2$ were regarded as obese.

Blood samples were collected from all patients in order to measure thyroid hormones (TSH, fT4), lipid profile, and glucose and insulin. All blood specimens were collected in the morning between 08:00 and 10:00 after 10-hour fasting. Insulin measurement was performed using the chemiluminescence method on an Advia Siemens Centaur XP device (Ireland). Fasting blood glucose was measured using the spectrophotometric method on an Advia Siemens 1800 (Japan) device. Homeostatic Model Assessment Insulin Resistance (HOMA-IR) was calculated using the following formula: fasting plasma glucose ( $\mathrm{mmol} / \mathrm{L}) \mathrm{x}$ fasting insulin (mUI/L) / 22.5 (18). TSH (reference range: 0.27-4.2 $\mu \mathrm{lU} / \mathrm{mL}$ ) and fT4 (reference range: 11-26 pmol/L) concentrations were measured via chemiluminescence methods with an Abbott Architect i4000 (USA) device. $\mathrm{TC}(\mathrm{mg} / \mathrm{dL})$, high-density lipoprotein cholesterol (HDL-C, $\mathrm{mg} / \mathrm{dL}), \mathrm{LDL}-\mathrm{C}(\mathrm{mg} / \mathrm{dL})$ and TC $(\mathrm{mg} / \mathrm{dL})$ concentrations were measured using photometric methods on an Abbott Architect c8000 (USA) device.

\section{Statistical Analysis}

Statistical analysis was performed on SPSS version 21 (SPSS Inc., Chicago, IL). The Shapiro-Wilk test was used to examine normality. Pearson and Spearmen correlation coefficients were calculated (in accordance with normality of distribution) to determine relationships between variables. Multiple linear regression analysis with stepwise selection was used for more reliable assessment of the relationships between TSH and fT4, and gender, age, anthropometric measurements, carbohydrate and lipid parameters related to obesity. $P$ values less than 0.05 were regarded as statistically significant.

\section{Results}

One hundred (57 girls, 43 boys) obese children and adolescents were included in the study. The mean age of the subjects was $11.43 \pm 2.64$ years. Descriptive statistics of our variables are given in Table I.

Analysis between $\mathrm{fT} 4$ and TSH values and other parameters measured in the study revealed no significant correlations for fT4, whereas fasting glucose $(r=0.265$; $p=0.008)$, (Figure 1) and cholesterol ( $r=0.220 ; p=0.028)$ (Figure 2) levels were significantly and positively correlated with TSH values (Table II).

Multiple linear regression analysis was performed with fT4 as a dependent variable, but none of our independent variables demonstrated any significant results. However, fasting glucose and cholesterol emerged as significant independent variables when TSH was defined as the dependent variable. The multiple linear regression model was $\mathrm{TSH}=0.047 *$ fasting glucose $+0.012 *$ cholesterol 
Table I. Main anthropometric, biochemical and hormonal parameters in obese patients

\begin{tabular}{|l|l|}
\hline & Mean \pm SD \\
\hline Age (years) & $11.43 \pm 2.64$ \\
\hline Weight $(\mathrm{kg})$ & $65.37 \pm 16.47$ \\
\hline Weight SDS & $2.76 \pm 0.70$ \\
\hline Height $(\mathrm{cm})$ & $149.21 \pm 13$ \\
\hline Height SDS & $0.69 \pm 1.20$ \\
\hline BMI SDS & $2.60 \pm 0.40$ \\
\hline fT4 (pmol/L) & $14.45 \pm 1.97$ \\
\hline TSH ( $\mu$ IU/mL) & $3.60 \pm 1.79$ \\
\hline Glucose (mg/dL) & $88.27 \pm 6.69$ \\
\hline Insulin (mUI/L) & $15.02 \pm 6.95$ \\
\hline HOMA-IR & $3.29 \pm 1.63$ \\
\hline Total cholesterol (mg/dL) & $167.77 \pm 31.47$ \\
\hline HDL-cholesterol (mg/dL) & $47.96 \pm 9.48$ \\
\hline LDL-cholesterol (mg/dL) & $101.54 \pm 26.92$ \\
\hline Triglyceride (mg/dL) & $121.72 \pm 47.33$ \\
\hline
\end{tabular}

BMI: Body Mass index, SDS: Standard Deviation score, fT4: Free thyroxin, TSH: Thyroid-stimulating hormone, HOMA-IR: Homeostatic Model Assessment Insulin Resistance, kg: kilogram, cm: centimeter

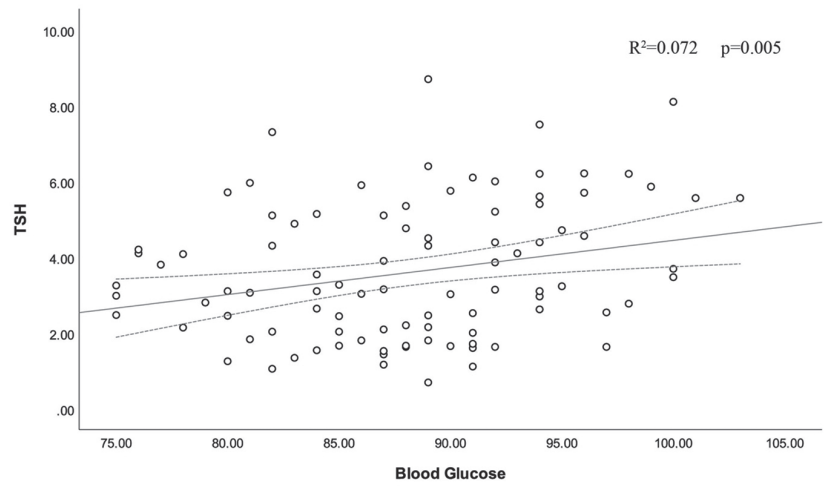

Figure 1. Scatter plot of thyroid-stimulating hormone and blood glucose

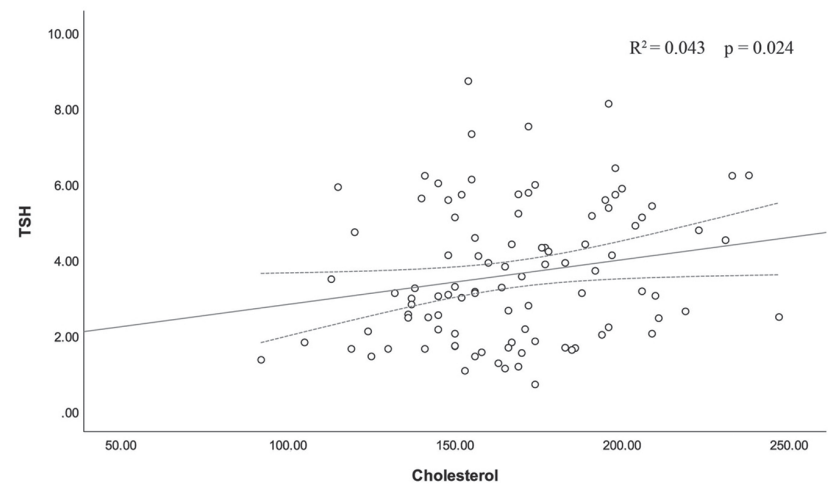

Figure 2. Scatter plot of thyroid-stimulating hormone and cholesterol
- $5.008(p=0.002)$, showing that a one-unit increase in fasting glucose raises increases TSH by 0.047 units, while a one-unit increase in cholesterol values raises TSH by 0.012 units (Table III).

\section{Discussion}

TSH levels in the current study were positively correlated with blood glucose and TC levels in a group of otherwise healthy obese pediatric patients. Multiple regression analysis revealed that $\mathrm{TSH}$ levels were directly affected by fasting glucose and cholesterol levels. However, fT4 levels were not associated with any of the parameters measured. Although we did not investigate causal relationships, the fact that TSH levels were associated with glucose and cholesterol levels while fT4 levels were not, may indicate that obesity has an initial effect on central thyroid function, which may lead to the development of metabolic pathologies.

The effects of thyroid hormones on energy balance and adipose tissue have been the subject of considerable research in recent years. Several recent cross-sectional studies have reported associations between thyroid hormones and obesity (4,5,19-23). Levels of cyclic adenosine monophosphate (AMP), a second messenger for many hormones including TSH and TRH, are closely associated with energy balance and the production/use of adenosine triphosphate (ATP). The correlation between TSH and blood glucose levels may indicate a complex relationship in terms of energy production and thyroid levels. Although TSH elevation may represent a simple response to increased glucose, aimed at regulating metabolism to compensate for and utilize the ATP-producing glucose in tissues, there may also be a more complex explanation. In the context of insulin resistance in obese patients, ATP depletion may develop in cells, leading to a decrease in the production of the second messenger c-AMP by adenylate cyclase. Liver cells are one of the main targets of thyroid hormones, and the action of these hormones in hepatocytes would be affected by depletion of cyclic AMP. The clinical result of this would be hepatocyte unresponsiveness to thyroid hormones, and an increase in TSH levels could be required to compensate for this decrease. These may represent the first steps in a progressive series of events culminating in TSH resistance $(24,25)$. Other studies of obese children show that only a minority suffer from autoimmune thyroiditis, while most demonstrate moderately increased TSH levels without thyroid disease $(10,26)$. Similarly, Dekelbab et al. (27) reported a higher prevalence of mild elevation of TSH values, in the absence of autoimmune thyroid disease, in a group of obese children compared to normal weight 
Table II. Relationships between various parameters and the levels of free thyroxin and thyroid-stimulating hormone

\begin{tabular}{|c|c|c|c|c|c|c|c|c|}
\hline & & Age & Weight & Weight SDS & Height & Height SDS & BMI SDS & Glucose \\
\hline \multirow[t]{2}{*}{ fT4 } & $\mathbf{R}$ & -0.036 & -0.148 & -0.088 & -0.112 & -0.015 & -0.141 & 0.003 \\
\hline & $\mathbf{p}$ & 0.719 & 0.143 & 0.382 & 0.267 & 0.883 & 0.160 & 0.978 \\
\hline \multirow[t]{2}{*}{ TSH } & $\mathbf{R}$ & 0.146 & 0.143 & 0.113 & 0.092 & -0.057 & 0.112 & 0.265 \\
\hline & $\mathbf{p}$ & 0.147 & 0.156 & 0.263 & 0.361 & 0.576 & 0.269 & $0.008^{*}$ \\
\hline & & Insulin & HOMA-IR & Cholesterol & HDL & LDL & Triglyceride & \\
\hline \multirow{2}{*}{ fT4 } & $\mathbf{R}$ & -0.119 & -0.126 & 0.008 & -0.063 & 0.096 & -0.115 & - \\
\hline & $\mathbf{p}$ & 0.237 & 0.212 & 0.934 & 0.533 & 0.343 & 0.253 & - \\
\hline \multirow[t]{2}{*}{ TSH } & $\mathbf{R}$ & 0.141 & 0.195 & 0.220 & 0.015 & 0.183 & 0.165 & - \\
\hline & $\mathbf{p}$ & 0.163 & 0.051 & $0.028^{*}$ & 0.885 & 0.069 & 0.100 & - \\
\hline
\end{tabular}

Table III. Multiple linear regression analysis results with TSH as a dependent variable

\begin{tabular}{|l|l|l|l|l|l|l|}
\hline & & & & & \multicolumn{2}{l|}{$\mathbf{9 5 . 0 \%} \mathrm{Cl}$ for $\beta$} \\
\cline { 5 - 8 } & & Std. Error & t & p & Lower & Upper \\
\hline (Constant) & -5.008 & 2.469 & -2.028 & 0.045 & -9.909 & -0.107 \\
\hline Fasting glucose & 0.074 & 0.026 & 2.898 & 0.005 & 0.023 & 0.125 \\
\hline Cholesterol & 0.012 & 0.005 & 2.29 & 0.024 & 0.002 & 0.023 \\
\hline TSH $=0.047$ * Fasting Glucose +0.012 * Cholesterol $-5.008, \mathrm{n}=100, \mathrm{R} 2=0.119, \mathrm{~F}=6.561, \mathrm{p}=0.002$ & & & \\
\hline
\end{tabular}

control groups. Stichel et al. (28) determined a significant increase in childhood obesity TSH and T3 levels, although in most cases these increases cannot be explained by thyroid autoimmunity or iodine deficiency. Further controlled studies are therefore required to explain our findings, which are far from conclusive, given that many other factors (such as iodine deficiency, and thyroid autoimmunity) capable of altering thyroid levels were not evaluated in our study.

Some studies have reported slightly greater elevation in TSH levels in obese individuals compared to normal weight subjects, and have detected a positive association between TSH levels and BMI and weight change $(10,29)$. Reinehr and Andler (30) observed a moderate increase in peripheral thyroid hormones $(\mathrm{T} 3, \mathrm{~T} 4)$ and TSH levels in obese children. TSH elevation exhibited no significant correlation with $\mathrm{BMI}$ (or any other anthropometric measurement) in the present study. However, TSH was significantly correlated with cholesterol levels. Multiple regression analysis results also indicated that a one-unit increase in cholesterol values corresponded to a 0.012-unit increase in TSH levels. Although various studies have investigated the relation of thyroid function and lipid profiles in obese and overweight pediatric patients, the results have been inconsistent (31). Grandone et al. (20) reported no correlation between TSH levels and HDL-C and TGs. However, consistent with our findings, Aeberli et al. (12) reported that TSH levels in obese pediatric patients exhibited a significant positive correlation with TC cholesterol and LDL-C.

We determined a significant positive correlation between TSH and fasting glucose levels, which was also apparent at multiple regression analysis, a one-unit increase in fasting glucose being found to cause an increase of 0.047 units in TSH. However, analysis of relationships between HOMA-IR and insulin levels with fT4 and TSH revealed no significant correlations. Although experimental studies have shown that thyroid hormones may impact insulin sensitivity by influencing the expression or activation of uncoupling protein, $\beta$ adrenergic receptor and peroxisome proliferatoractivated receptor- $\gamma(32)$, our findings may suggest that TSH levels (and therefore thyroid function) are affected much earlier than insulin. If so, then it is plausible to suggest that early TSH changes are in fact a contributor to the insulin resistance seen in obese patients. Future studies would benefit from long-term follow-up of thyroid and insulin levels in children with obesity in order to elucidate which causes the other, or to determine whether a causal relationship exists between these two crucial parameters of human metabolism. 
Both hyperthyroidism and hypothyroidism are capable of resulting in impaired glucose tolerance in hepatic, muscle, and adipose tissues (33). Although a number of different studies have investigated the relation between thyroid function and insulin resistance in children and adults, the reported findings regarding the link between insulin resistance and hypothyroidism or hyperthyroidism are inconsistent (34). Maratou et al. (35) reported similar levels of insulin resistance in cases of hypothyroidism and of subclinical hyperthyroidism. However, associations between hypothyroidism and insulin resistance subsequently progressing to Metabolic syndrome in adults have been reported by a number of authors $(36,37)$.

The limitations of our study include the absence of a control group; however, our aim was to assess the relationships of measured parameters in obese children and adolescents. Our analyses are not therefore necessarily affected by the lack of a control group. Nevertheless, a control group would have provided an opportunity to observe the differences in the relationships among parameters (or lack thereof) between obese and nonobese subjects, and this must be regarded as a limitation. Second, this is a retrospective single-center study with all the restrictions associated with such studies. Finally, we were unable to analyze various other factors that may have affected thyroid levels, such as iodine deficiency, and autoimmune thyroiditis.

\section{Conclusion}

The purpose of this study was to determine fT4 and TSH concentrations in obese children and adolescents and to investigate potential correlations between such parameters as anthropometric measurements, glucose levels and lipid profile. Fasting blood glucose and cholesterol were positively correlated with TSH, while none of the parameters investigated were associated with fT4 levels. We believe that our findings will make a significant contribution to the existing literature by showing that obesity may exert a central effect on thyroid function, before the emergence of any effects on insulin levels and anthropometric characteristics. Since the physiopathology of thyroid function changes in childhood obesity and the effects of thyroid function on lipid and carbohydrate metabolism are still controversial, further studies are required for an improved understanding of the association between thyroid function and obesity.

\section{Ethics}

Ethics Committee Approval: The author assert that all procedures contributing to this work comply with the ethical standards of the relevant national guidelines on human experimentation (Başkent University) and with the Helsinki Declaration of 1975, as revised in 2008, and have been approved by the institutional committees of Başkent University (approval number: KA-19/27).

Informed Consent: Informed consent was obtained.

Peer-review: Externally and internally peer-reviewed.

Financial Disclosure: The author declared that this study received no financial support.

\section{References}

1. Ogden $\mathrm{CL}$, Carroll MD, Lawman HG, et al. Trends in obesity prevalence among children and adolescents in the United States, 1988-1994 through 2013-2014. JAMA 2016;315:2292-9.

2. Unger R, Kreeger L, Christoffel KK. Childhood obesity: medical and familial correlates and age of onset. Clin Pediatr (Phila) 1990;29:368-73.

3. Lee H, Pantazis A, Cheng P, Dennisuk L, Clarke PJ, Lee JM. The association between adolescent obesity and disability incidence in young adulthood. J Adolesc Health 2016;59:472-8.

4. Reinehr T, Isa A, De Sousa G, Dieffenbach R, Andler W. Thyroid hormones and their relation to weight status. Horm Res 2008;70:51-7.

5. Reinehr T, de Sousa G, Andler W. Hyperthyrotropinemia in obese children is reversible after weight loss and is not related to lipids. / Clin Endocrinol Metab 2006;91:3088-91.

6. Marras V, Casini MR, Pilia S, et al. Thyroid function in obese children and adolescents. Horm Res Paediatr 2010; 73:193-7.

7. Radetti G, Kleon W, Buzi F, et al. Thyroid function and structure are affected in childhood obesity. I Clin Endocrinol Metab 2008;93:4749-54.

8. Rapa A, Monzani A, Moia S, et al. Subclinical hypothyroidism in children and adolescents: a wide range of clinical, biochemical, and genetic factors involved. I Clin Endocrinol Metab 2009;94:2414-20

9. Fox CS, Pencina MJ, D'Agostino RB, et al. Relations of thyroid function to body weight. Arch Intern Med. 2008;168:587-92.

10. Reinehr T. Obesity and thyroid function. Mol Cell Endocrinol 2010;316:165-71.

11. Franks PW, Hanson RL, Knowler WC, Sievers ML, Bennett PH, Looker HC. Childhood obesity, other cardiovascular risk factors, and premature death. N Engl J Med 2010;362:485-93.

12. Aeberli I, Jung A, Murer SB, et al. During rapid weight loss in obese children, reductions in TSH predict improvements in insulin sensitivity independent of changes in body weight or fat. J Clin Endocrinol Metab 2010;95:5412-8.

13. Parlak A, Çetinkaya Ş. Çocuklarda obezitenin oluşumunu etkileyen faktörler. Fırat Salık Hizmetleri Dergisi 2007;2:27-33.

14. Mutlu RGY, Özsu E, Çizmecioğlu FM, Hatun Ş. Mildly elevated TSH levels in obese children: What kind of problem is this?. Turk Arch Ped 2011;46:33-6.

15. Karakurt F, Mustafa K, Burak U. Tiroid Fonksiyonları Obezite için Bir Risk Faktörü Müdür? Yeni Tıp Dergisi 2009;26:27. 
16. TorunE, CindemirE, Özgen I, ÖktemF. Subclinical hypothyroidism in obese children. Dicle Medical Journal 2013;40:5-8.

17. Neyzi O, Bundak R, Gökçay G, Calabrò P, Perrone L, Del Giudice EM. Reference Values for Weight, Height, Head Circumference, and Body Mass Index in Turkish Children. I Clin Res Pediatr Endocrinol 2015;7:280-93.

18. Matthews DR, Hosker JP, Rudenski AS, Naylor BA, Treacher DF, Turner RC. Homeostasis model assessment: insulin resistance and beta-cell function from fasting plasma glucose and insulin concentrations in man. Diabetologia 1985;28:412-9.

19. Yadav J, Jain N, Dayal D. Alterations of thyroid function in overweight and obese children: An update. Indian J Child Health 2018;5:145-50.

20. Grandone A, Santoro N, Coppola F, Calabrò P, Perrone L, del Giudice EM. Thyroid function derangement and childhood obesity: an Italian experience. BMC Endocr Disord 2010;10:8

21. Wolters B, Lass N, Reinehr T. TSH and free triiodothyronine concentrations are associated with weight loss in a lifestyle intervention and weight regain afterwards in obese children. Eur J Endocrinol 2013;168:323-9.

22. Knudsen N, Laurberg P, Rasmussen LB, et al. Small differences in thyroid function may be important for body mass index and the occurrence of obesity in the population. I Clin Endocrinol Metab 2005:90:4019-24.

23. Shalitin S, Yackobovitch-Gavan M, Phillip M. Prevalence of thyroid dysfunction in obese children and adolescents before and after weight reduction and its relation to other metabolic parameters. Horm Res 2009;71:155-61.

24. Venditti P, Balestrieri M, Di Meo S, De Leo T. Effect of thyroid state on lipid peroxidation, antioxidant defences, and susceptibility to oxidative stress in rat tissues. J Endocrinol 1997;155:151-7.

25. Neuschwander-Tetri BA, Caldwell SH. Nonalcoholic steatohepatitis: summary of an AASLD Single Topic Conference. Hepatology 2003;37:1202-19.
26. Reinehr T, Hinney A, de Sousa G, Austrup F, Hebebrand I, Andler W. Definable somatic disorders in overweight children and adolescents. I Pediatr 2007;150:618-22.

27. Dekelbab BH, Abou Ouf HA, Jain I. Prevalence of elevated thyroid-stimulating hormone levels in obese children and adolescents. Endocr Pract 2010;16:187-9.

28. Stichel $H$, Allemand $D$, Grüters $A$. Thyroid function and obesity in children and adolescents. Horm Res 2000;54:14-9.

29. Pearce EN. Thyroid hormone and obesity. Curr Opin Endocrinol Diabetes Obes 2012;19:408-13.

30. Reinehr T, Andler $W$. Thyroid hormones before and after weight loss in obesity. Arch Dis Child 2002;87:320-3.

31. Pacifico L, Anania C, Ferraro F, Andreoli GM, Chiesa C. Thyroid function in childhood obesity and metabolic comorbidity. Clin Chim Acta 2012;413:396-405.

32. Nader NS, Bahn RS, Johnson MD, Weaver AL, Singh R, Kumar S. Relationships between thyroid function and lipid status or insulin resistance in a pediatric population. Thyroid 2010;20:1333-9.

33. Gierach M, Gierach J, Junik R. Insulin resistance and thyroid disorders. Endokrynol Pol 2014;65:70-6.

34. Lambadiari V, Mitrou P, Maratou E, et al. Thyroid hormones are positively associated with insulin resistance early in the development of type 2 diabetes. Endocrine 2011;39:28-32.

35. Maratou E, Hadjidakis DJ, Kollias A, et al. Studies of insulin resistance in patients with clinical and subclinical hypothyroidism. Eur J Endocrinol 2009;160:785-90.

36. Guo S. Insulin signaling, resistance, and metabolic syndrome: insights from mouse models into disease mechanisms. I Endocrinol 2014;220:T1-T23.

37. Kadiyala R, Peter R, Okosieme OE. Thyroid dysfunction in patients with diabetes: clinical implications and screening strategies. Int J Clin Pract 2010;64:1130-9. 